\title{
Endoscopic Endonasal Transodontoid Approach for Degenerative Pseudotumor of the Craniocervical Junction
}

\author{
Andrew S. Venteicher ${ }^{1, *(1)} \quad$ Ezequiel Goldschmidt ${ }^{2, *}$ \\ Carl H. Snyderman ${ }^{3}$ Paul A. Gardner ${ }^{2}$ \\ ${ }^{1}$ Department of Neurosurgery, University of Minnesota, Minneapolis, \\ Minnesota, United States \\ ${ }^{2}$ Department of Neurological Surgery, University of Pittsburgh \\ Medical Center, Pittsburgh, Pennsylvania, United States \\ ${ }^{3}$ Department of Otolaryngology, University of Pittsburgh Medical \\ Center, Pittsburgh, Pennsylvania, United States
}

\author{
Michael M. McDowell ${ }^{2}$ Eric W. Wang ${ }^{3}$
}

J Neurol Surg B 2019;80(suppl S4):S368-S369.

\begin{abstract}
Address for correspondence Paul A. Gardner, MD, Department of Neurological Surgery, 200 Lothrop Street, Suite B400, University of Pittsburgh Medical Center, Pittsburgh, PA 15213, United States (e-mail: gardpa@upmc.edu).
\end{abstract}

\begin{abstract}
Keywords

- transodontoid

- endoscopic endonasal approach

- craniocervical junction

- retroodontoid degenerative pseudotumor

- periodontoid pannus

Ventral masses of the craniocervical junction threaten the medulla and upper spinal cord leading to lower cranial nerve dysfunction and myelopathy. Traditional transoral and newer endonasal approaches can access ventral pathology in this region, though both remain challenging due to the competing goals of achieving sufficient decompression, yet mitigating risk to nearby critical neurovascular structures. Transoral approaches have traditionally been avoided for degenerative pseudotumor which generally slowly regresses following posterior fixation. Here, we present two cases of patients with significant retroodontoid degenerative pseudotumor and pannus causing dysphagia and myelopathy. The first patient was found with a large broad pannus requiring a wide decompression extending from lower clivus to inferior aspect of the $\mathrm{C} 1$ arch and odontoid process. The second patient had a more focal mass effect due to pannus and synovial cyst at the level of the inferior half of $\mathrm{C} 1$ and midodontoid. Both patients underwent an endoscopic endonasal transodontoid approach for immediate decompression followed by a posterior C1-C2 fusion. In these surgical videos, we highlight anatomic considerations in this critical area, demonstrate nuances of technique, and outline strategies to avoid complications and maximize exposure.

The link to the video can be found at: https://youtu.be/19I-GQYGIr4.
\end{abstract}

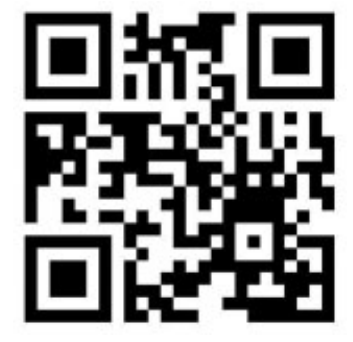

Co-first authors. www.thieme.com/skullbasevideos

www.thieme.com/jnlsbvideos received

March 30, 2019

accepted after revision

August 25, 2019

published online

November 4, 2019
DOI https://doi.org/

10.1055/s-0039-1700892.

ISSN 2193-6331. (c) 2019 Georg Thieme Verlag KG
Stuttgart · New York

License terms

c) $(1) \$$ 

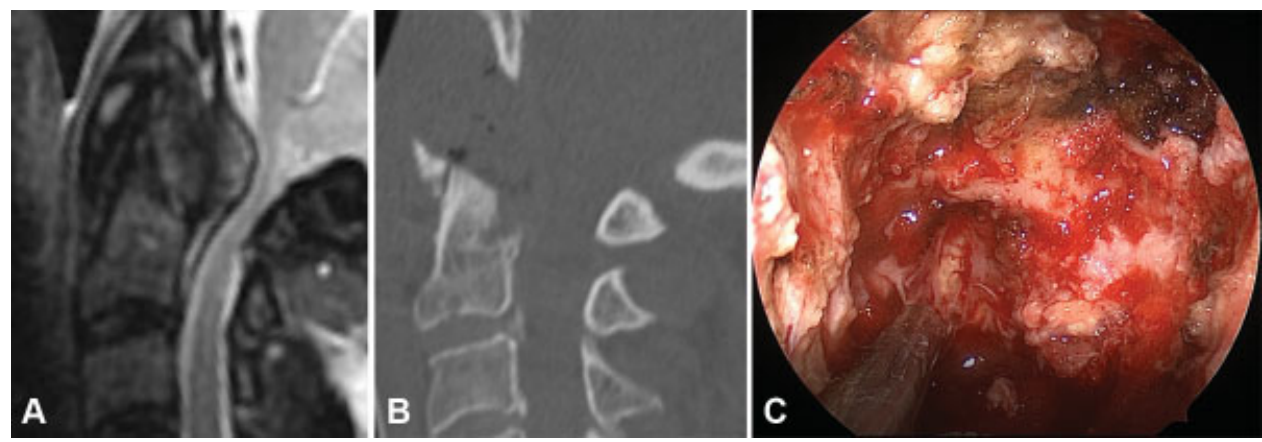

Fig. 1 Patient 1 with broad retroodontoid pseudotumor causing cervicomedullary stenosis. (A) Preoperative MRI T2. (B) Postoperative CT. (C) Endoscopic view after pannus was resected. CT, computed tomography; MRI, magnetic resonance imaging.
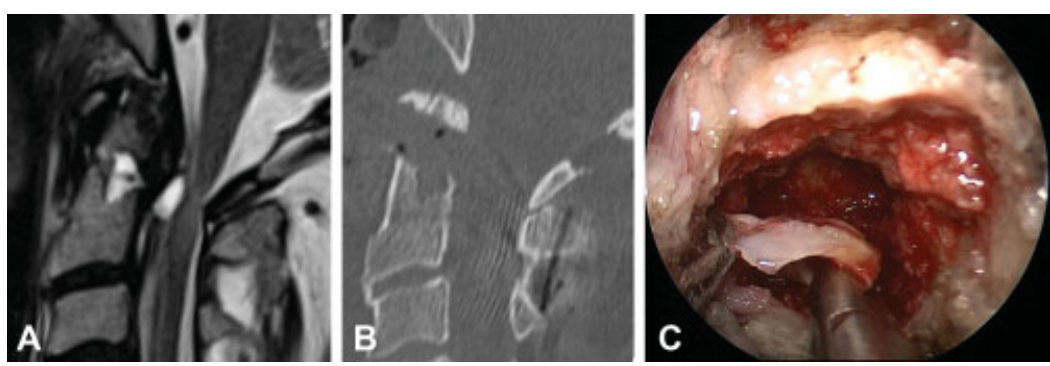

Fig. 2 Patient 2 with retroodontoid pseudotumor and synovial cyst causing cervicomedullary stenosis. (A) Preoperative MRI T2.

(B) Postoperative CT. (C) Endoscopic view removing synovial cyst wall. CT, computed tomography; MRI, magnetic resonance imaging.

\section{Publication Comments}

The authors present two cases of endonasal endoscopic resection of the odontoid for pannus and a synovial cyst. Use of a myofascial flap is demonstrated.

Jeffery Sorenson, MD

University of Tennessee Health Science Center

Memphis, TN
Conflict of Interest

Dr. Gardner reports other from SPIWay, LLC, outside the submitted work; Dr. Snyderman reports other from SPIWay, LLC, outside the submitted work.

\section{Acknowledgments}

The authors thank the Rhoton Collection for access to anatomic photographs used in this video. We also thank Paul Stanick for assistance in producing this video. 